\title{
Mapping of a complicated familial spastic paraplegia to locus SPG4 on chromosome $2 p$
}

Olivier Heinzlef, Caroline Paternotte, Florence Mahieux, Jean-François Prud'homme, Joëlle Dien, Michel Madigand, Jean Pouget, Jean Weissenbach, Etienne Roullet, Jamilé Hazan

Service de Neurologie, Hôpital Tenon, 4 rue de Chine, 75020 Paris,

France

O Heinzlef

F Mahieux

E Roullet

\section{URA CNRS 1922}

Généthon, 1 rue de

l'Internationale, 91000

Evry, France

C Paternotte

J-F Prud'homme

J Weissenbach

J Hazan

Service de Neurologie, Hôpital de

Saint-Brieuc,

Saint-Brieuc, France

J Dien

$M$ Madigand

Service de Neurologie, Hôpital La Timone, Marseille, France J Pouget

Correspondence to: Dr Heinzlef or Dr Hazan

Received 31 July 1997 Revised version accepted for publication 14 October 1997

\begin{abstract}
Autosomal dominant familial spastic paraplegia (AD-FSP) is a degenerative disorder of the central motor system characterised by progressive spasticity of the lower limbs. AD-FSP has been divided into pure and complicated forms. Pure AD-FSP is genetically heterogeneous; three loci have been mapped to chromosomes 14q (SPG3), 2p (SPG4), and 15q (SPG6), whereas no loci responsible for complicated forms have been identified to date. Here we report linkage to the SPG4 locus in a three generation family with AD-FSP complicated by dementia and epilepsy. Assuming that both forms of AD-FSP are caused by mutations involving the same FSP gene, analysis of recombination events in this family positions the SPG4 gene within a $0 \mathrm{cM}$ interval flanked by loci D2S2255 and D2S2347. $(\mathcal{F M e d}$ Genet 1998;35:89-93)
\end{abstract}

Keywords: familial spastic paraplegia (FSP); dementia; epilepsy; SPG4 locus

Familial spastic paraplegia (FSP) is a clinically and genetically heterogeneous group of neurodegenerative disorders mainly characterised by progressive spasticity of the lower limbs (spastic gait, hyperreflexia, clonus, and Babinski sign). ${ }^{1}$ The basic pathological features of FSP are degeneration of the crossed pyramidal tracts and thinning of the dorsal columns. FSP is commonly divided into two forms ${ }^{2}$ depending on whether spasticity occurs in isolation ("pure" FSP, MIM 182600) $)^{3}$ or associated with a wide range of additional symptoms ("complicated" FSP), such as mental retardation (MIM 270850, 270950, 182690), ichthyosis, optic atrophy (MIM 182830), dementia (MIM 182830), epilepsy, ataxia, deafness (MIM 312910, 182690), and peripheral neuropathies (MIM 182800). FSP can be inherited in an autosomal dominant (AD-FSP), autosomal recessive (AR-FSP), or $\mathrm{X}$ linked (X-FSP) manner. Within each inheritance pattern, FSP exhibits both clinical variability and genetic heterogeneity. Genetic heterogeneity was first described for two different forms of $\mathrm{X}$ linked FSP; in a family manifesting X-FSP associated with mental retardation and optic atrophy, the disease gene was mapped to Xq28 markers (locus SPG1), ${ }^{4}$ while linkage to the $\mathrm{Xq}$ 1-22 region (locus SPG2) was reported in a kindred with pure X-FSP. ${ }^{5}$ Pure AD-FSP and AR-FSP were also shown to be genetically heterogeneous. ${ }^{6} 7 \mathrm{~A}$ locus for AR-FSP has been mapped to chromosome 8 (SPG5) ${ }^{7}$ and three loci responsible for pure AD-FSP have been localised on chromosomes 14q (SPG3), ${ }^{6} 2 p$ (SPG4), ${ }^{89}$ and 15q (SPG6). ${ }^{10}$

Complicated forms of FSP are rare and are usually transmitted in an autosomal recessive pattern although some cases showing autosomal dominant or $\mathrm{X}$ linked inheritance have also been described. ${ }^{3}$ Here we report a three generation family with AD-FSP complicated by dementia and epilepsy, in which we found significant linkage of the disease gene to the SPG4 locus on chromosome $2 \mathrm{p}$. Assuming that both forms of FSP result from mutations in the same gene, recombinant analysis in this complicated AD-FSP kindred allowed us to refine the SPG4 region and to place the gene within a 0 centimorgan (cM) interval flanked by loci D2S2255 and D2S2347.

\section{Subjects and methods}

PATIENTS

Fourteen members of a three generation French family (family $\mathrm{CM}$, fig 1) were examined by the authors $(\mathrm{OH}, \mathrm{MM}, \mathrm{JD}$, and JP) and seven met the disease criteria defined as follows: (1) subjects with progressive spastic paraplegia showing pyramidal signs in the lower limbs (spasticity, increased reflexes, and Babinski sign) and an asymptomatic patient with bilateral extensor plantar reflexes were considered to be affected; (2) the asymptomatic family members with normal neurological examination were considered unaffected. Disability was assessed on a three point scale as previously described ${ }^{11}: 1=$ normal gait or very slight stiffness in the legs; $2=$ unable to run, but able to walk without help; $3=$ unable to walk without help or wheelchair bound. Living affected members with memory impairment underwent the following neuropsychological tests: Mini-mental state (MMS) to 
Table 1 Summary of clinical features in affected members

\begin{tabular}{llllll}
\hline & Age at onset & $\begin{array}{l}\text { Age at first } \\
\text { examination }\end{array}$ & $\begin{array}{l}\text { Severity of } \\
\text { SP }\end{array}$ & $\begin{array}{l}\text { Cognitive } \\
\text { impairment }\end{array}$ & Epilepsy \\
\hline II.6 (proband) & 52 & 65 & 3 & Dementia & + \\
II.3 & 56 & 67 & 3 & $?+$ & 0 \\
II.2 & 45 & 60 & 3 & + & + \\
III.6 & 30 & 36 & 2 & 0 & 0 \\
III.1 & Unknown & 34 & 2 & + & 0 \\
III.2 & $32-35$ & 32 & 1 & 0 & 0 \\
III.5 & 20 & 30 & 2 & + & +
\end{tabular}

$\star$ Unaware of diagnosis. †Memory impairment but died before neuropsychological tests $\mathrm{SP}=$ spastic paraplegia. $1=$ normal gait; $2=$ unable to run, able to walk without help; $3=$ unable to walk without help or wheelchair bound.

evaluate global cognitive performance ${ }^{12}$; ReyOsterrieth complex figure exploring constructional abilities ${ }^{13}{ }^{14}$; Wechsler memory scale $^{15}$; Raven's progressive matrices which provide an evaluation of IQ based on non-verbal reasoning ${ }^{16}$; and WAIS-R which consists of several subtests performed to determine verbal and non-verbal IQs. ${ }^{17}$ Informed consent was obtained from each family member before blood samples were drawn.

\section{GENOTYPING}

DNA was extracted from whole blood using standard procedures. Polymerase chain reactions (PCR) were carried out as previously described. ${ }^{6}$ Four amplification products, generated with separate primer sets on identical DNA samples, were co-precipitated and comigrated in a single lane of $6 \%$ polyacrylamide denaturing gel. Separated products were then transferred to Pall membranes and hybridised successively with non-radiolabelled (ECL, Amersham) PCR primers as previously reported. ${ }^{18}$

\section{LINKAGE ANALYSIS}

Two point lod scores between FSP and SPG4 markers were calculated by MLINK of the
LINKAGE package (version 5.1) ${ }^{19}$ under the assumption of an autosomal dominant FSP gene with a frequency of $10^{-4}$ and equal female and male recombination rates. Based on the clinical evaluation, we chose to estimate the pairwise lod scores using penetrance values of $100 \%$ and liability classes. Five liability classes were obtained from the cumulative age of onset curve previously designed ${ }^{8}: 0.17$ for subjects from 0 to 19 years old, 0.32 for $20-24$ years, 0.55 for $25-30$ years, 0.92 for $31-51$ years, and 0.99 for subjects over 51 years. Marker allele frequencies were assumed to be equal. Simulation analyses with extensive alterations of the allele frequencies did not modify the conclusions of the linkage analyses. ${ }^{20}$

\section{Results}

CASE REPORTS

The clinical characteristics of the affected family members are shown in table 1 . In the kindred presented here, seven subjects are affected with FSP; four of these have cognitive impairment or dementia and three have epilepsy. It should be noted that none of the unaffected subjects complained of memory loss, had abnormal Mini-mental state (MMS), or had epilepsy.

\section{Patient II. 6 (proband)}

This 69 year old woman had been unsteady since she was 52 and was first referred when she was 62 . At that time she could not walk for more than 10 minutes. She was treated for two years for urinary urgency. She had slight memory impairment. Examination showed severe spasticity of the legs with brisk reflexes in the lower $(+++)$ and upper limbs $(+)$, and clonus of the ankles. There was no motor or sensory deficit. She had bilateral Babinski

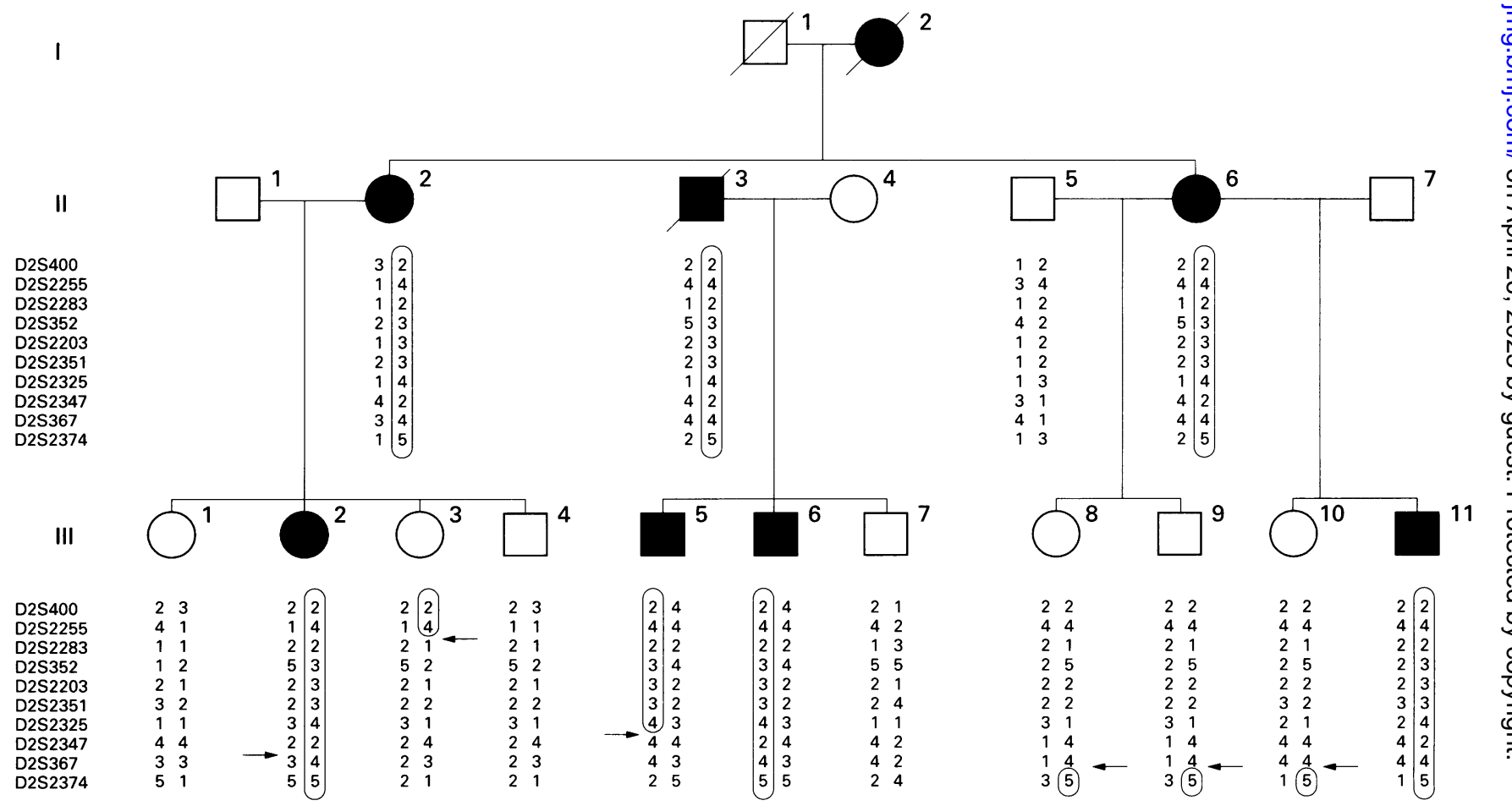

Figure 1 Pedigree of family CM. Affected subjects are represented by black symbols and unaffected family members by open symbols. Boxes indicate disease chromosomes. Recombination events are marked with an arrow. 
signs. Cerebral and medullary magnetic resonance imaging (MRI), visual and auditory evoked potentials, electromyography, and cerebrospinal fluid (CSF) analysis were normal. Sensory evoked potentials (SEPs) by stimulation of the nerve trunks of the lower limbs were consistent with spinal cord involvement but cervical SEPs were normal. Serum vitamin B12 and folates were normal; TPHA, VDRL, and HTLV-1 antibody tests were negative. Plasma long chain fatty acid analysis was negative. Muscle biopsy was normal. Neuropsychological examination disclosed a slight decrease in verbal ability (WAIS verbal IQ of 102 compared with an IQ of 124 on Raven's progressive matrices) and poor verbal fluency. Her performance on the verbal memory scale was normal (memory quotient (MQ) of 124). During the next three years she experienced a gradual deterioration in memory and ability to walk. A new neuropsychological examination performed three years later was unchanged, except for a deterioration of memory abilities (MQ of 112). In April 1995 she had a generalised seizure and antiepileptic treatment was started. She walked with one stick and began to have spatial disorientation. Neuropsychological examination showed a reduction in conceptual and constructional abilities, while memory performance remained stable. Between April 1995 and June 1996 she had a marked decline in motor and cognitive abilities. Walking became impossible. She did not recognise her children. Examination showed bilateral grasping. Neuropsychological evaluation showed massive aphasia and visual agnosia. Memory impairment involved both short term and long term memory. There was marked temporospatial disorientation. The MMS was 9/30. She eventually met all DSM-III-R criteria for dementia. Repeat cerebral MRI showed widening of the cerebral sulci with dilatation of the ventricular structure.

Patient I.2

This woman died at the age of 80 . She had progressive gait and walking difficulties in her 60 s but was never examined by a neurologist.

\section{Patient II. 3}

This 67 year old man had had walking difficulties since he was 56 . He could not walk more than 5 metres, had urinary urgency, and complained of memory loss. On examination he had spasticity in the legs with pyramidal reflexes in all four limbs and impairment of short term and long term memory. He also had pes cavus and ichthyosis. The MMS was $29 / 30$ but he refused extensive neuropsychological examination. He died suddenly two years later.

\section{Patient II.2}

This 63 year old woman had had walking difficulties since she was 45 . When she was first examined in January 1994, she could walk 2 $\mathrm{km}$ with a stick. She did not complain of memory loss or urinary problems. Examination showed pes cavus, a proximal motor deficit of thigh flexion ( $4 / 5$ on the MRC scale), spasticity, and brisk reflexes with spreading in the lower limbs and bilateral Babinski signs. There was no sensory deficit and the MMS was $30 / 30$. On neuropsychological examination no abnormalities were found in verbal or constructional abilities. Her attention was slightly impaired, especially in the spatial component. There was an impairment of visual memory which was limited to delayed recall. In July 1994 she began to complain of urinary urgency with loss of control. At the same time, she developed dysarthria and language difficulties. A cerebral infarct was suspected but investigations were negative. CT scan of the head showed atrophy and slight leukoaraiosis. There were generalised theta delta waves on the electroencephalogram. In August 1994 she was treated for partial motor epilepsy and in October 1994 developed a status epilepticus. MRI of the brain disclosed widening of the sulci with dilatation of the ventricular structures. The CSF was normal.

\section{Patient III.2}

This 35 year old woman was first seen in January 1994. She did not complain of any symptoms and her examination was normal. Although she again denied any symptoms, re-examination in January 1997 disclosed bilateral Babinski signs.

\section{Patient III. 5}

This 30 year old man had a generalised seizure at 17 and began to have difficulties in walking at $20 . \mathrm{He}$ had urinary urgency and complained of memory loss. Examination showed slight spasticity in the lower limbs with bilateral Babinski signs. The MMS was normal. On neuropsychological examination he had impairment in episodic and semantic memory (the IQ was 105 on Raven's progressive matrices) and his performance on the WAIS vocabulary subtest was impaired (age scaled score=5). On the Wechsler memory scale (revised), his index score was 86 for verbal memory, 126 for visual memory, 94 for attention, but only 80 for delayed recall. He was at the 90th centile for the copy test of the Rey figure and the 20th centile for recall.

\section{Patient III. 6}

This 39 year old man began to complain of walking difficulties at the age of 30 . Neurological examination showed spasticity of the lower limbs without weakness, but with bilateral Babinski signs and brisk reflexes in the lower limbs.

\section{Patient III. 11}

This 34 year old man did not complain of walking problems but recognised that he had memory impairment. Examination showed bilateral Babinski signs, brisk reflexes in all four limbs, bilateral hypoacusis, and pes cavus. The MMS was $27 / 30$ and neuropsychological examination showed impairment in episodic and semantic memory while attention was preserved. His IQ was 110 on Raven's progressive matrices, but his performance on the WAIS vocabulary subtest was poor (age scaled score=7). On the Wechsler memory scale 
Table 2 Pairwise lod scores between SPG4 markers and FSP in family CM

\begin{tabular}{|c|c|c|c|c|c|c|c|c|c|c|}
\hline \multirow[b]{2}{*}{ Locus } & \multirow[b]{2}{*}{ Penetrance } & \multicolumn{9}{|c|}{ Recombination fraction } \\
\hline & & 0.00 & 0.01 & 0.05 & 0.10 & 0.20 & 0.30 & 0.40 & $\theta \max$ & $Z \max$ \\
\hline \multirow[t]{2}{*}{ D2S2283 } & $100 \%$ & 2.25 & 2.21 & 2.03 & 1.81 & 1.33 & 0.82 & 0.30 & 0.00 & 2.25 \\
\hline & LC & 2.15 & 2.11 & 1.94 & 1.73 & 1.26 & 0.77 & 0.27 & 0.00 & 2.15 \\
\hline \multirow[t]{2}{*}{ D2S352 } & $100 \%$ & 3.47 & 3.41 & 3.16 & 2.84 & 2.15 & 1.40 & 0.58 & 0.00 & 3.47 \\
\hline & LC & 3.23 & 3.17 & 2.94 & 2.63 & 1.98 & 1.27 & 0.51 & 0.00 & 3.23 \\
\hline \multirow[t]{2}{*}{ D2S2203 } & $100 \%$ & 3.13 & 3.07 & 2.83 & 2.51 & 1.85 & 1.15 & 0.44 & 0.00 & 3.13 \\
\hline & LC & 2.89 & 2.84 & 2.60 & 2.31 & 1.68 & 1.02 & 0.37 & 0.00 & 2.89 \\
\hline \multirow[t]{2}{*}{ D2S2351 } & $100 \%$ & 1.89 & 1.90 & 1.88 & 1.75 & 1.35 & 0.85 & 0.31 & 0.01 & 1.90 \\
\hline & LC & 2.03 & 2.00 & 1.88 & 1.70 & 1.26 & 0.77 & 0.27 & 0.00 & 2.03 \\
\hline \multirow{2}{*}{ D2S2325 } & $100 \%$ & 3.49 & 3.43 & 3.19 & 2.87 & 2.18 & 1.42 & 0.60 & 0.00 & 3.49 \\
\hline & LC & 3.26 & 3.20 & 2.96 & 2.66 & 2.00 & 1.29 & 0.53 & 0.00 & 3.26 \\
\hline \multirow[t]{2}{*}{ D2S2347 } & $100 \%$ & -4.73 & -0.60 & 0.11 & 0.36 & 0.43 & 0.29 & 0.10 & 0.17 & 0.44 \\
\hline & LC & -4.06 & -0.48 & 0.15 & 0.35 & 0.39 & 0.25 & 0.08 & 0.16 & 0.40 \\
\hline
\end{tabular}

Lod scores were calculated at different recombination fractions, assuming complete penetrance or using the liability classes (LC) described in the Methods.

(revised), he obtained an index score of 84 for verbal memory, 87 for visual memory, 93 for delayed recall, and 101 for attention. He was at the 50th centile in the copy subtest and only the 15 th centile in the recall subtest of the Rey figure.

\section{HAPLOTYPE AND LINKAGE ANALYSIS}

Four microsatellite markers from the three different AD-FSP loci were initially chosen from a published set ${ }^{21}$ and tested for linkage to FSP in family CM: D14S1055, D14S255, D14S269, and D14S1018 for locus SPG3; D2S352, D2S367, D2S2347, and D2S2283 for locus SPG4; and D15S1035, D15S128, D15S156, and D15S122 for locus SPG6. The chromosome $14 q$ and $15 q$ candidate regions were entirely excluded $(Z<-2)$ by two point analyses in family $C M$, whereas maximum lod scores of 3.49 and 3.26 at $\theta=0$ were obtained with locus D2S2325, assuming complete penetrance and using liability classes, respectively. A total of 10 microsatellite markers spanning the SPG4 candidate interval were then analysed to confirm the linkage to this region. The pairwise data between AD-FSP and six informative chromosome $2 p$ loci are presented in table 2 .

The haplotype was constructed with all 10 loci and is shown in fig 1 . The order of the markers presented in the haplotype is consistent not only with the physical map of the region (J Hazan, unpublished data) but also with the analysis of recombination events in 13 families displaying AD-FSP linked to the SPG4 locus. ${ }^{11}$ The analysis of recombination events within the haplotype positions the FSP causing gene in family $\mathrm{CM}$ within a $0 \mathrm{cM}$ interval between loci D2S2255 and D2S2347..$^{21}$ The distal border defined by the crossover at D2S2255 in unaffected subject III. 3 is consistent with recombination events in affected members from the other SPG4 linked families (C Paternotte, unpublished data). The recombinant III. 5 would narrow the critical interval on the proximal side at locus D2S2347 and thus would enable the refinement of the SPG4 candidate region.

\section{Discussion}

We investigated AD-FSP complicated by cognitive impairment and epilepsy. Of the seven patients with FSP, four had cognitive impairment or dementia and three had epilepsy. This clinical pattern is consistent with the intrafamilial hetereogeneity previously described in complicated FSP families. ${ }^{22}{ }^{23}$ Few families with AD-FSP associated with epilepsy or an abnormal EEG have been reported to date..$^{24-26}$

In a previous study of subclinical cognitive impairment in FSP patients, all the people affected with complicated AD-FSP had cognitive deficits on neuropsychological tests, ${ }^{27}$ such as lack of concentration, slowness to respond to the examiner, poor capacity for retaining new information, and temporospatial disorientation. On the other hand, pedigrees displaying AD- or AR-FSP complicated by dementia or clinically evident cognitive impairment are rare. ${ }^{22}{ }_{28-30}$ In an Irish kindred reported previously, ${ }^{22}$ one affected member died of dementia and six had cognitive deficits with predominant visuospatial impairment in neuropsychological studies. Similarly, in family $\mathrm{CM}$, one patient had severe dementia while three had cognitive impairment, but the neuropsychological deficit seems rather different from that described in the Irish kindred. Furthermore, cognitive impairment cosegregates with epilepsy in family CM. To our knowledge, the association of AD-FSP, dementia, and epilepsy has not been described previously.

In the present study, we report the first localisation of a gene responsible for a form of AD-FSP complicated by epilepsy and cognitive impairment. Our data clearly establish significant linkage between the disease causing gene in family CM and the SPG4 locus known to be associated with pure AD-FSP. ${ }^{8}$ At this stage of the study, three hypotheses might account for this result: (1) allelic heterogeneity, (2) locus heterogeneity involving distinct genes responsible for pure and complicated AD-FSP and located within the SPG4 region, and (3) a contiguous gene syndrome. (1) The two different forms of FSP may be the result of allelic heterogeneity at a single locus, as reported for X-FSP at the SPG2 locus. ${ }^{31}$ Similarly, in AD-FSP, allelic heterogeneity could explain the mapping of the gene responsible for this complicated form of FSP to the SPG4 locus. (2) Within the SPG4 interval, there could be one gene responsible for pure AD-FSP and another one involved in the complicated form described here. (3) The coexistence of dementia and epilepsy with FSP in family CM may 
also suggest a contiguous gene syndrome. A deletion spanning the AD-FSP gene (SPG4) and one or several gene(s) involved in dementia and epilepsy could also account for the observed phenotype. However, no molecular microdeletion within the SPG4 region has been detected so far in affected members of this kindred (J Hazan, unpublished data).

Although none of these hypotheses has been confirmed or ruled out so far, allelic heterogeneity already shown for X-FSP at the SPG2 locus $^{31}$ seems the most probable. Assuming this hypothesis, the analysis of recombination events in this pedigree places the SPG4 gene within a $0 \mathrm{cM}$ interval flanked by loci D2S2255 and D2S2347. The reduction of the SPG4 interval from $4 \mathrm{cM}^{8}$ to $0 \mathrm{cM}$ is the result of a cluster of non-recombining markers in the last version of the published genetic map. ${ }^{21}$ However, the flanking markers of the cluster, D2S2255 and D2S2347, are separated by a physical distance estimated to be $2.5 \mathrm{Mb}(\mathrm{J}$ Hazan, unpublished data), while the physical distance spanning the former SPG4 interval flanked by loci D2S400 and D2S367 was estimated as $5 \mathrm{Mb}^{32}$

Inter- and intrafamilial variations in the age of onset have been observed in several families with AD-FSP. ${ }^{83-36}$ It should be noted that the age of onset in family $C M$ was earlier in generation III than in generation II. Anticipation of age at onset has been previously suggested, ${ }^{8738}$ but may be explained by an observation bias. ${ }^{11}$ However, cognitive impairment seems to occur earlier in the third generation of the reported pedigree. Only the isolation of the SPG4 gene and the identification of the mutation(s) in different families will provide further insight into the questions of anticipation and allelic heterogeneity.

The first two authors contributed equally to this work. We are grateful to the family members for their participation in this study. We are indebted to Annie Kurtze and Marie-Josée Manifacier for performing the neuropsychological tests. We thank facier for performing the neuropsychological tests. We thank
Susan Cure, David Young, and Steve Holland for critical reading of the manuscript. This work was supported by the Associing of the manuscript. This work was supported
ation Française contre les Myopathies (AFM).

1 Reid E. Pure hereditary spastic paraplegia. 7 Med Genet 1997;34:499-503.

2 Sutherland JM. Familial spastic paraplegia. In: Vinken PJ, Bruyn GW, eds. Handbook of clinical neurology. Vol 22. Amsterdam: North Holland Publishing Company, 1975: 421-31.

3 McKusick VA. Mendelian inheritance in man. 10th ed. Baltimore: The Johns Hopkins University Press, 1992.

4 Kenwrick S, Ionasescu V, Ionasescu G, et al. Linkage studies of X-linked recessive spastic paraplegia using DNA probes. Hum Genet 1986;73:264-6.

5 Keppen LD, Leppert MF, O'Connell $\mathrm{P}$, et al. Etiological heterogeneity in X-linked spastic paraplegia. Am $\mathcal{F}$ Hum Genet 1987;41:933-43.

6 Hazan J, Lamy C, Melki J, Munnich A, de Recondo J, Weissenbach J. Autosomal dominant familial spastic paraplegia is genetically heterogeneous and one locus maps to is genetically heterogeneous and one locu

7 Hentati A, Pericak-Vance MA, Hung WY, et al. Linkage of "pure" autosomal recessive familial spastic paraplegia to "pure" autosomal recessive familial spastic paraplegia to
chromosome 8 markers and evidence of genetic locus hetchromosome 8 markers and evidence of gen
erogeneity. Hum Mol Genet 1994;3:1263-7.
8 Hazan J, Fontaine B, Bruyn RPM, et al. Linkage of a new locus for autosomal dominant familial spastic paraplegia to chromosome 2p. Hum Mol Genet 1994;3:1569-73.

9 Hentati A, Pericak-Vance MA, Lennon F, et al. Linkage of a locus for autosomal dominant familial spastic paraplegia to locus for autosomal dominant familial spastic paraplegia to

10 Fink JK, Wu CB, Jones SM, et al. Autosomal dominant familial spastic paraplegia: tight linkage to chromosome 15q. Am f Hum Genet 1995;56:188-92.

11 Dürr A, Davoine CS, Paternotte C, et al. Phenotype of autosomal dominant spastic paraplegia linked to chromosome 2. Brain 1996;119:1487-96.

12 Folstein SE, Folstein MF, McHugh PR. "Mini-mental state": a practical method for grading the cognitive state of patients for the clinician. $\mathcal{F}$ Psychiatr Res $1975 ; 12: 189-98$.

13 Osterrieth PA. Le test de copie d'une figure complexe. Arch Psychol 1945;30:205-9.

14 Rey A. L'examen clinique en psychologie. 2nd ed. Paris: Presses Universitaires de France, 1964.

15 Wechsler DA. A standardized memory scale for clinical use. f Psychol 1945;19:87-95.

16 Raven JC. Guide to the standard progressive matrices. London HK Lewis, 1960.

17 Wechsler DA. Wechsler Adult Intelligence Scale (revised). New York: Psychological Corporation, 1981

18 Vignal A, Gyapay G, Hazan J, et al. Nonradioactive multiplex procedure for genotyping of microsatellite markers. In: Adolph KW, ed. Methods in molecular genetics. Vol 1. New York: Academic Press, 1993:211-21.

19 Lathrop GM, Lalouel JM, Julier C, Ott J. Multilocus linkage analysis in humans: detection of linkage and estimation of recombination. Am $\mathcal{F}$ Hum Genet 1985;37:482-98.

20 Freimer NB, Sandkuijl LA, Blower SM. Incorrect specification of marker allele frequencies: effects on linkage analysis. Am F Hum Genet 1993;52:1 102-10.

21 Dib C, Fauré S, Fizames C, et al. A comprehensive genetic map of the human genome based on 5,264 microsatellites. Nature 1996;380:152-4.

22 Webb S, Coleman D, Hutchinson J, Hutchinson M. "Pure" autosomal dominant spastic paraplegia with late-onset dementia: a family study. Ann Neurol 1996;40:530.

23 White KD, Ince PJ, Bashir R, et al. Chromosome 2p linked autosomal dominant hereditary spastic paraparesis with late onset dementia. A clinical, genetic and pathological case report. F Neurol 1997;244:S31.

24 Gilman S, Horenstein S. Familial amyotrophic dystonic paraplegia. Brain 1964;87:57-66

25 Kuroda S, Kazahaya Y, Otsuki S, Takahashi S. Familia spastic paraplegia with epilepsy. Acta Med Okayama 1985, 39:113-17.

26 Yih JS, Wang SJ, Su MS, et al. Hereditary spastic paraplegia associated with epilepsy, mental retardation and hearing impairment. Paraplegia 1993;31:408-11.

27 Tedeschi G, Alloca S, Di Constanzo A, et al. Multisystem involvement of the central nervous system in Strumpell's disease. A neurological and neuropsychological study. $\mathcal{f}$ Neurol Sci 1991;103:55-60.

28 Woster-Drought C, Greenfield J, McMenemey W. A form of familial presenile dementia with spastic paralysis. Brain 1944;67:38-43

29 Pridmore S, Gyaneshwar R, Abusah P. Hereditary spastic paraplegia with dementia. Aust N Z F Psychiatry 1995;29: 678-82.

30 Nakamura A, Izumi K, Umehara F, et al. Familial spastic paraplegia with mental impairment and thin corpus callosum. F Neurol Sci 1995;131:35-42.

31 Bonneau D, Rozet JM, Bulteau C, et al. X linked spastic paraplegia (SPG2): clinical heterogeneity at a single gene locus. $\mathcal{F}$ Med Genet 1993;30:381-4.

32 De Jonghe P, Krols L, Michalik A, et al. Pure familial spastic paraplegia: clinical and genetic analysis of nine Belgian paraplegia: clinical and genetic analysis

33 Harding AE. Hereditary "pure" spastic paraplegia: a clinical and genetic study of 22 families. $\mathcal{F}$ Neurol Neurosurg Psychiatry 1981;44:871-83.

34 Harding AE. Classification of the hereditary ataxias and paraplegias. Lancet 1983;i:1151-5.

35 Dürr A, Brice A, Serdaru M, et al. The phenotype of pure autosomal dominant spastic paraplegia. Neurology 1994;44: 1274-7.

36 The Hereditary Spastic Paraplegia Working Group. Hereditary spastic paraplegia: advances in genetic research. Neurology 1996;46:1507-14.

37 Lennon F, Gaskell PC, Scott WK, et al. Genetic studies in familial spastic paraparesis: heterogeneity results and evidence for anticipation in chromosome 2 SPG. $\mathrm{Am} f$ evidence for anticipation

38 Bürger J, Metzke H, Paternotte C, Schilling F, Hazan J, Reis A. Autosomal dominant spastic paraplegia with anticipation maps to a 4-cM interval on chromosome 2p21-p24 in a large German family. Hum Genet 1996;98:371-5. 